
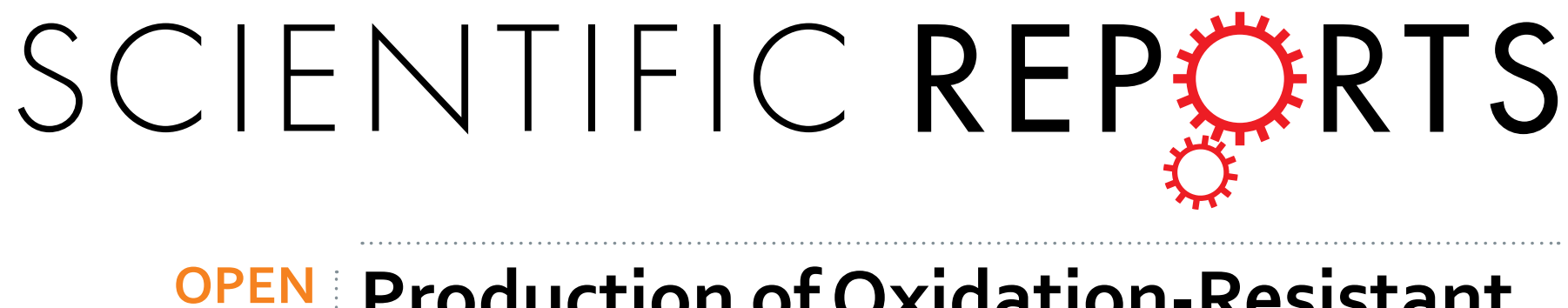

\title{
Production of Oxidation-Resistant Cu-Based Nanoparticles by Wire Explosion
}

Received: 09 July 2015

Accepted: 16 November 2015

Published: 16 December 2015

\author{
Go Kawamura ${ }^{1,2}$, Samuel Alvarez ${ }^{1}$, Ian E. Stewart ${ }^{1}$, Matthew Catenacci ${ }^{1}$, Zuofeng Chen $^{1,3}$ \& \\ Yoon-Cheol $\mathrm{Ha}^{1,4}$
}

The low performance or high cost of commercially available conductive inks limits the advancement of printed electronics. This article studies the explosion of metal wires in aqueous solutions as a simple, low-cost, and environmentally friendly method to prepare metallic nanoparticles consisting of $\mathrm{Cu}$ and $\mathrm{Cu}$ alloys for use in affordable, highly conductive inks. Addition of $0.2 \mathrm{M}$ ascorbic acid to an aqueous explosion medium prevented the formation of $\mathrm{Cu}_{2} \mathrm{O}$ shells around $\mathrm{Cu}$ nanoparticles, and allowed for the printing of conductive lines directly from these nanoparticles with no post-treatment. Cu alloy nanoparticles were generated from metal wires that were alloyed as purchased, or from two wires of different metals that were twisted together. Cu nanoparticles alloyed with $1 \% \mathrm{Sn}, 5 \% \mathrm{Ag}, 5 \% \mathrm{Ni}$ and $30 \% \mathrm{Ni}$ had electrical conductivities similar to $\mathrm{Cu}$ but unlike $\mathrm{Cu}$, remained conductive after $24 \mathrm{hrs}$ at $85^{\circ} \mathrm{C}$ and $85 \% \mathrm{RH}$.

Printed electronics has the potential to enable rapid prototyping and low-cost production of functional circuits. Achieving this vision requires the development of low-cost inks that can deliver the desired level of performance and environmental stability with minimal post-processing. Current conductive inks based on organometallic precursors or metal nanoparticles (NPs) exhibit near-bulk-metal conductivity $\left(1.0 \times 10^{-7} \Omega \mathrm{m}\right)^{1,2}$. This high conductivity is usually achieved only after heat treatments at temperatures greater than $200^{\circ} \mathrm{C}$ under reducing conditions to sinter and connect NPs ${ }^{3,4}$. These high post-processing temperatures limit the number of compatible substrates or processing systems ${ }^{5-8}$. Current conductive inks also rely on the use of $\mathrm{Au}$ and Ag due to the high conductivity of these metals, and their stability in air and water. However, the reliance on rare noble metals makes conductive inks fairly expensive, a problem which will only get worse as the use of these inks becomes more common. Conductive polymers require little post processing and are potentially a sustainable alternative to noble metal-based inks, but these materials are much less conductive $\left(>10^{-2} \Omega \mathrm{m}\right)^{9,10}$.

$\mathrm{Cu}$ NPs are a promising replacement for $\mathrm{Au}$ and $\mathrm{Ag}$ NPs because $\mathrm{Cu}$ is 100 times cheaper $\left(\$ 7 \mathrm{~kg}^{-1}\right)$ than $\mathrm{Ag}$ and possesses a conductivity $\left(1.68 \times 10^{-8} \Omega \mathrm{m}\right)$ between $\mathrm{Au}\left(2.44 \times 10^{-8} \Omega \mathrm{m}\right)$ and $\mathrm{Ag}\left(1.59 \times 10^{-8} \Omega \mathrm{m}\right)$. The main problem with $\mathrm{Cu}$ NPs is their sensitivity to oxygen ${ }^{11,12}$. Cu oxides on the surface of NPs are usually removed by sintering at temperatures greater than $200^{\circ} \mathrm{C}$ in a reducing atmosphere (e.g. $\mathrm{H}_{2}$ ), and the oxidation of Cu after sintering reduces the electrical conductivity of the final device. Attempts to solve the oxidation problem include coating $\mathrm{Cu}$ NPs with graphene ${ }^{13}$, poly(N-vinylpyrrolidone) (PVP) ${ }^{14-16}$, and $\mathrm{Ag}^{17}$. However, graphene increases the contact resistance between NPs, PVP requires high sintering temperatures for removal, and the deposition of Ag adds cost.

$\mathrm{Cu}$ alloy NPs could be a viable alternative to Cu NPs coated with protective layers. NP's of several copper alloys have been produced to date, including $\mathrm{Cu}-\mathrm{Au}, \mathrm{Cu}-\mathrm{Ag}, \mathrm{Cu}-\mathrm{Ni}, \mathrm{Cu}-\mathrm{Al}$, and $\mathrm{Cu}-\mathrm{Zn}{ }^{18-23}$. However, many of the preparation procedures require toxic chemicals, and their detailed corrosion resistance has yet to be reported.

Wire explosion (WE) is one of the simplest, cost effective, versatile, and environmentally friendly methods for the production of metal NPs. It is also easy to scale up while retaining the quality of NPs. Instantaneous evaporation of macroscopic metal wires is only performed by huge electric current to form nanoparticles. Thus WE consumes only metal wires and electricity, and generates little waste ${ }^{24,25}$. More than 20 different metal-based NPs,

${ }^{1}$ Duke University, Department of Chemistry, Durham, North Carolina 27708, United States. ${ }^{2}$ Toyohashi University of Technology, Department of Electrical and Electronic Information Engineering, 1-1 Hibarigaoka, Tempaku-cho, Toyohashi, Aichi 441-8580, Japan. ${ }^{3}$ Tongji University, Department of Chemistry, Shanghai 200092, PR China. ${ }^{4}$ Korea Electrotechnology Research Institute, Creative and Fundamental Research Division, Changwon 642-120, Korea. Correspondence and requests for materials should be addressed to G.K. (email: gokawamura@ee.tut.ac.jp) 
A

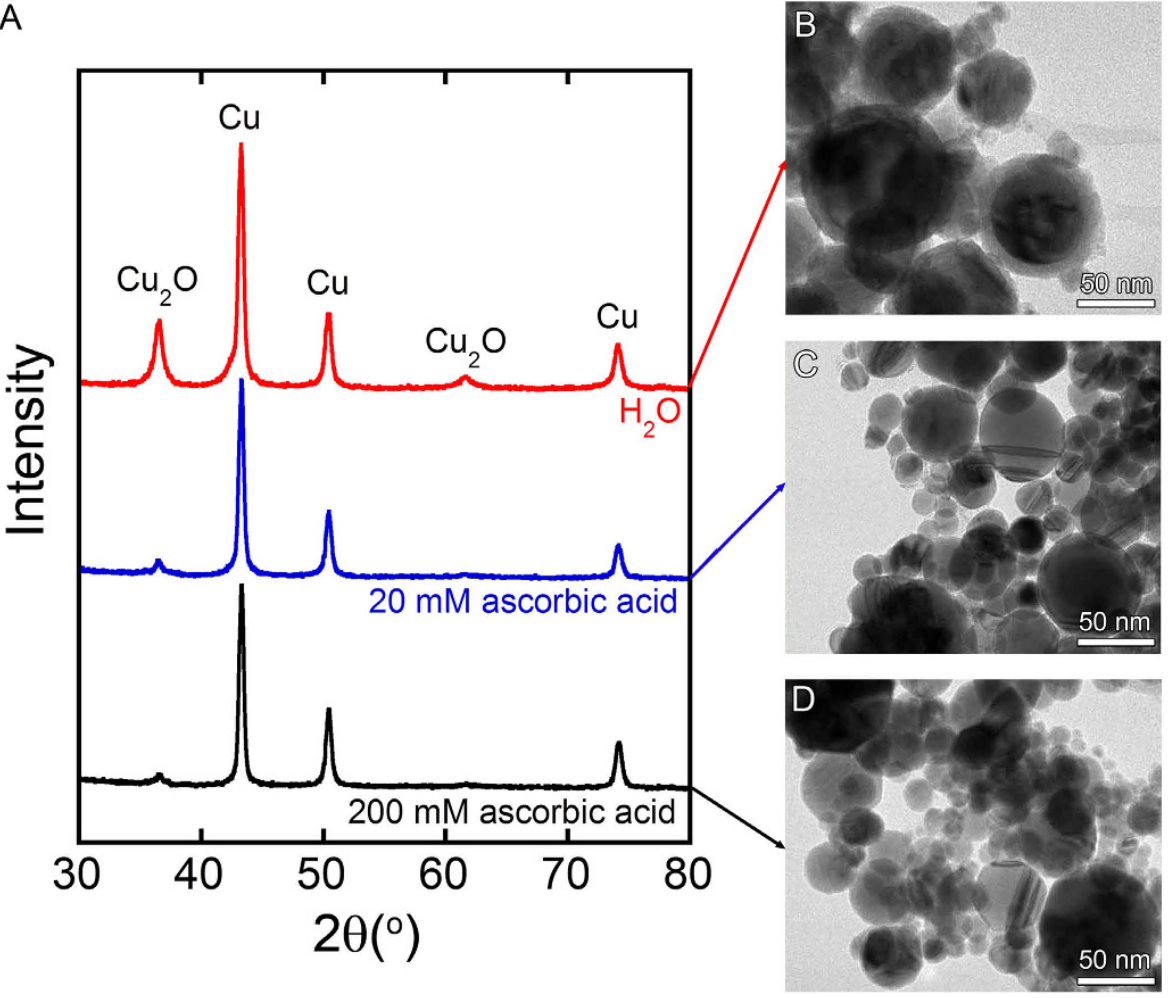

Figure 1. (A) XRD patterns of samples prepared by WE of $\mathrm{Cu}$ wires in deionized water and water containing 20 and $200 \mathrm{mM}$ ascorbic acid. (B-D) show the corresponding TEM images.

including $\mathrm{Cu}$ and several of its alloys have been prepared by WE in various gaseous and liquid environments ${ }^{26-37}$. Disadvantages of WE relative to chemical methods include the fact that it is more difficult to produce a NP product that is monodisperse in size. Although this may not be a problem for the use of these NPs in conductive inks, the NPs can be classified by sedimentation or centrifugation if required. To date, there have been no studies on the electrical properties and corrosion resistance of $\mathrm{Cu}$ alloy NPs produced by WE.

This work reports the preparation of several novel $\mathrm{Cu}$ alloy NPs with WE, including $99 \mathrm{Cu}-1 \mathrm{Sn}(1 \mathrm{Sn}), 95 \mathrm{Cu}-5 \mathrm{Ag}$ $(5 \mathrm{Ag}), 95 \mathrm{Cu}-5 \mathrm{Ni}(5 \mathrm{Ni}), 70 \mathrm{Cu}-30 \mathrm{Ni}(30 \mathrm{Ni})$ and $70 \mathrm{Cu}-30 \mathrm{Zn}(30 \mathrm{Zn})$. NPs were prepared from metal wires that were either alloyed as purchased or from two separate wires that were twisted together. The composition of the NPs could be changed simply by twisting different numbers of wires together with different compositions. Wires were exploded in water with ascorbic acid added as a mild reducing agent to decrease the oxidation of $\mathrm{Cu}$. This method to produce NPs generates no waste except for the nontoxic aqueous solution of ascorbic acid. Films of as-prepared NPs exhibited electrical resistivities as low as $5.25 \times 10^{-5} \Omega \mathrm{m}$ after drying in air at room temperature. The resistivity could be lowered further to $1.64 \times 10^{-6} \Omega \mathrm{m}$ by sintering at $200^{\circ} \mathrm{C}$ in $\mathrm{H}_{2}$. Conductive lines drawn using $\mathrm{Cu}$ alloy $\mathrm{NPs}$ were more resistant to corrosion than $\mathrm{Cu}$ NPs at high temperature and under humid conditions.

\section{Results and Discussion}

Cu NPs prepared by WE. As shown by the XRD pattern in Fig. 1, the NPs prepared by WE of Cu wires in deionized water are composed of a mixture of $\mathrm{Cu}$ and $\mathrm{Cu}_{2} \mathrm{O}$ (Fig. $1 \mathrm{~A}$ red). The TEM image shows the formation of core-shell $\mathrm{Cu} @ \mathrm{Cu}_{2} \mathrm{O}$ NPs with diameters less than $100 \mathrm{~nm}$, and shells less than $12 \mathrm{~nm}$ in thickness (Fig. 1B). When the sample was prepared in an aqueous solution containing $20 \mathrm{mM}$ ascorbic acid, much weaker $\mathrm{Cu}_{2} \mathrm{O}$ peaks were observed in the XRD pattern (Fig. 1A blue), and the TEM image showed the thickness of the $\mathrm{Cu}_{2} \mathrm{O}$ shell was $<1 \mathrm{~nm}$ (Fig. 1C). Increasing the ascorbic acid concentration to $200 \mathrm{mM}$ further suppressed the oxidation of $\mathrm{Cu}$ (Fig. 1A black and Fig. 1D). Ascorbic acid is sometimes used for reducing $\mathrm{Cu}$ ions to form $\mathrm{Cu}$ nanoparticles ${ }^{38-41}$. Required energy to reduce $\mathrm{Cu}$ ions by ascorbic acid is generated as heat by the explosion of wire in this work.

Previous work has studied the suppression of oxide formation during WE through the use of organic solvents or inert gases ${ }^{27}$. However, we found that the explosion of $\mathrm{Cu}$ NPs in organic solvents resulted in the formation of graphitic carbon on the surface of the NPs, presumably because of a large amount of carbon element in the solvent (Fig. 2A). These carbon layers will increase the contact resistance between NPs. For example, Cu NPs coated with graphitic carbon were previously prepared in a reducing flame synthesis, and the inkjet-printed lines displayed a relatively high electrical resistivity of $1 \times 10^{-2} \Omega \mathrm{m}^{13}$. Metal NPs prepared by WE in inert gas should be free of carbonaceous surface layers, but NPs prepared under gaseous conditions tend to aggregate (Fig. 2B). Due to this aggregation, the conductive lines drawn with the NPs are porous, and thus have low electrical conductivity ${ }^{42}$. The conductivity of the lines did not improve substantially after sintering at $200^{\circ} \mathrm{C}$ in $\mathrm{H}_{2}$ for $30 \mathrm{~min}$. This is because higher temperatures are needed to reduce the porosity significantly. 

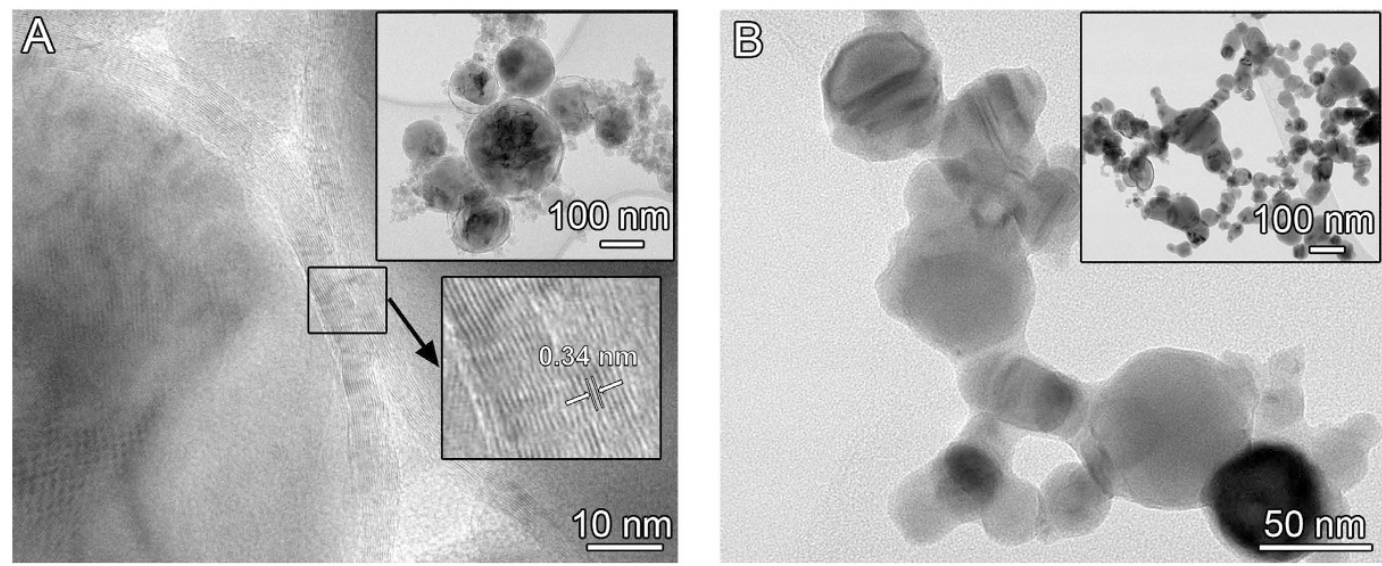

Figure 2. TEM images of NPs prepared by WE. (A) Cu NPs produced by explosion of Cu wire in ethanol are coated by graphitic carbon with an interlayer spacing of $0.34 \mathrm{~nm}$. (B) $\mathrm{Cu}$ NPs exploded in $\mathrm{N}_{2}$ gas are aggregated into clusters.

\begin{tabular}{|l|c|c|c|}
\hline Wire & Solution & Resistivity (before sintering) & Resistivity (after sintering) \\
\hline $\mathrm{Cu}$ & $\mathrm{H}_{2} \mathrm{O}$ & $\infty \Omega \mathrm{m}$ & $\infty \Omega \mathrm{m}$ \\
\hline $\mathrm{Cu}$ & $20 \mathrm{mM}$ ascorbic acid & $1.61 \times 10^{-2} \Omega \mathrm{m}$ & $2.38 \times 10^{-5} \Omega \mathrm{m}$ \\
\hline $\mathrm{Cu}$ & $200 \mathrm{mM}$ ascorbic acid & $8.25 \times 10^{-5} \Omega \mathrm{m}$ & $1.72 \times 10^{-6} \Omega \mathrm{m}$ \\
\hline $\mathrm{Cu}$ & $200 \mathrm{mM}$ ascorbic acid $+\mathrm{PVP}$ & $5.60 \times 10^{-4} \Omega \mathrm{m}$ & $5.23 \times 10^{-6} \Omega \mathrm{m}$ \\
\hline
\end{tabular}

Table 1. Resistivity of lines drawn with Cu NPs prepared by WE in 4 different solutions.

Surprisingly, there has been no previous attempt to prevent the oxidation of metal NPs exploded in water with a reducing agent. The fact that adding a reducing agent to the explosion medium does help to prevent the oxidation of the NPs points to the relatively unexplored potential of using chemical methods to control the surface chemistry of NPs produced with WE. Although we have not surveyed what other reducing agents can be used in this concept, agents with low molecular weights should be employed, eliminating the possibility to form carbonaceous surface layers or to get contaminated.

After drying at room temperature in air, the typical resistivity of the lines of $\mathrm{Cu}$ NPs produced with $200 \mathrm{mM}$ ascorbic acid was $8.25 \times 10^{-5} \Omega \mathrm{m}$. This resistivity decreased to $1.72 \times 10^{-6} \Omega \mathrm{m}$ after sintering at $200^{\circ} \mathrm{C}_{\text {in }} \mathrm{H}_{2}$ for 30 min. A much higher resistivity of $1.61 \times 10^{-2} \Omega \mathrm{m}$ was observed for the $\mathrm{Cu}$ NPs prepared using the $20 \mathrm{mM}$ ascorbic acid solution. This is presumably because the thin $\mathrm{Cu}_{2} \mathrm{O}$ shell $(<1 \mathrm{~nm}$ in Fig. $1 \mathrm{C})$ obstructed the conduction of electrons between Cu NPs. Sintering helped to reduce the $\mathrm{Cu}_{2} \mathrm{O}$ shell, and decreased the resistivity to $2.38 \times 10^{-5} \Omega \mathrm{m}$. In contrast, conductive lines drawn from the $\mathrm{Cu}-\mathrm{Cu}_{2} \mathrm{O}$ NPs prepared by WE in water without added ascorbic acid were not conductive before or after sintering. These results are summarized in Table 1. Clearly, the addition of ascorbic acid was critical to minimizing the resistivity of the metal lines.

In addition to the effect of surface oxide, we examined the effect of a polymeric stabilizer and particle size on the electrical resistivity of metal lines made from $\mathrm{Cu}$ NPs. To examine the effect of adding a polymeric stabilizer, copper wires were exploded in an aqueous solution containing $0.16 \mathrm{mM} \mathrm{PVP}\left(\right.$ molecular weight $=10^{4}$ ) and $200 \mathrm{mM}$ ascorbic acid. The resulting lines exhibited a resistivity 7 times higher $\left(5.60 \times 10^{-4} \Omega \mathrm{m}\right)$ than the samples without $\operatorname{PVP}\left(8.25 \times 10^{-5} \Omega \mathrm{m}\right)$, although there was not an observable difference in the size or dispersion of the NPs. Lines drawn with $200 \mathrm{mM}$ ascorbic acid solution containing $40 \mathrm{vol} \%$ of commercially available Cu alloy micro particles ( $50 \mu \mathrm{m}$ brass and $150 \mu \mathrm{m}$ bronze, Alfa Aesar) exhibited no electrical conductivity, even after sintering at $200^{\circ} \mathrm{C}$ under $\mathrm{H}_{2}$ for $30 \mathrm{~min}$. In both cases, the high resistivity was likely the result of poor electrical contact between the particles, either because of blocking due to PVP, or, in the case of the microparticles, because there are fewer points of contact, and those contacts might be covered by an oxide.

Cu alloy NPs prepared by WE. The morphology and size distribution of $\mathrm{Cu}$ alloy NPs were similar to those of $\mathrm{Cu}$ NPs. The elemental distribution in the $\mathrm{Cu}$ alloy NPs was also carefully investigated using $30 \mathrm{Ni}$ sample, because the large amount of Ni made the Ni detection by EDX easy. A fluctuation of Ni content was observed among NPs (Figure S1); however, all of the observed NPs (more than 20 NPs) contained a certain amount of Ni (5.53-49.0 mol\%).

Resistivities of conductive lines drawn using $\mathrm{Cu}$ and $\mathrm{Cu}$ alloy NPs prepared by WE in $200 \mathrm{mM}$ ascorbic acid solution are shown in Table 2 . The measured resistivities of the $1 \mathrm{Sn}, 5 \mathrm{Ag}, 5 \mathrm{Ni}$, and $30 \mathrm{Ni} \mathrm{Cu}$ alloy NPs before and after sintering were similar to those of Cu NPs made with $200 \mathrm{mM}$ ascorbic acid, with the lowest alloy content $1 \mathrm{Sn}$ exhibiting the best performance. This result makes sense given that the conductivity of $\mathrm{Cu}$ alloys generally increases with the concentration of $\mathrm{Cu}$. However, the resistivity of the $30 \mathrm{Zn}$ (brass) composition was a couple 


\begin{tabular}{|l|c|c|c|}
\hline Sample & Before sintering & After sintering & After corrosion test \\
\hline $\mathrm{Cu}$ & $8.25 \times 10^{-5} \Omega \mathrm{m}$ & $1.72 \times 10^{-6} \Omega \mathrm{m}$ & $1.02 \times 10^{-2} \Omega \mathrm{m}$ \\
\hline $1 \mathrm{Sn}$ & $3.49 \times 10^{-4} \Omega \mathrm{m}$ & $1.64 \times 10^{-6} \Omega \mathrm{m}$ & $3.85 \times 10^{-5} \Omega \mathrm{m}$ \\
\hline $5 \mathrm{Ag}$ & $5.25 \times 10^{-5} \Omega \mathrm{m}$ & $2.21 \times 10^{-6} \Omega \mathrm{m}$ & $4.13 \times 10^{-4} \Omega \mathrm{m}$ \\
\hline $5 \mathrm{Ni}$ & $1.14 \times 10^{-4} \Omega \mathrm{m}$ & $5.99 \times 10^{-6} \Omega \mathrm{m}$ & $4.74 \times 10^{-5} \Omega \mathrm{m}$ \\
\hline $30 \mathrm{Ni}$ & $9.09 \times 10^{-3} \Omega \mathrm{m}$ & $8.57 \times 10^{-6} \Omega \mathrm{m}$ & $7.67 \times 10^{-5} \Omega \mathrm{m}$ \\
\hline $30 \mathrm{Zn}$ & $4.76 \times 10^{0} \Omega \mathrm{m}$ & $3.78 \times 10^{-4} \Omega \mathrm{m}$ & $1.08 \times 10 \Omega \mathrm{m}$ \\
\hline
\end{tabular}

Table 2. Resistivity of lines drawn using $\mathrm{Cu}$ and $\mathrm{Cu}$ alloy NPs. The NPs were prepared by WE in $200 \mathrm{mM}$ ascorbic acid solution.

orders of magnitude higher than the other compositions. Formation of a $\mathrm{ZnO}$ shell on $30 \mathrm{Zn} \mathrm{NPs}$ was confirmed by XRD and TEM analysis (Figure S2), which is consistent with the much higher resistivity of 30Zn than the other pre-sintered samples. The sintering removed $\mathrm{Cu}_{2} \mathrm{O}$ peaks completely from XRD patterns of all samples, but $\mathrm{ZnO}$ peaks in $30 \mathrm{Zn}$ remained after sintering (Figs $3 \mathrm{~A}$ and $4 \mathrm{~B}$ ).

Figure 4 shows how the resistivity of lines made from NPs consisting of different alloys change under conditions which accelerate the corrosion of the metal $\left(85^{\circ} \mathrm{C}\right.$ and $\left.85 \% \mathrm{RH}\right)$. The resistivities measured in this experiment were not consistent with the results shown in Table 2. This was because different pieces of apparatus were used for these two experiments; the detailed conditions are described in the Methods section later. The resistivity of the $30 \mathrm{Zn}$ sample and pure $\mathrm{Cu}$ sample increased rapidly under these conditions. In contrast, the increase in the resistivity of the $1 \mathrm{Sn}, 5 \mathrm{Ag}, 5 \mathrm{Ni}$, and $30 \mathrm{Ni}$ lines were relatively slow. After $24 \mathrm{hrs}$ at $85^{\circ} \mathrm{C}$ and $85 \% \mathrm{RH}, 4.3,0.54,13$ and $11 \%$ of the initial conductivity was retained for the $1 \mathrm{Sn}, 5 \mathrm{Ag}, 5 \mathrm{Ni}$ and $30 \mathrm{Ni}$ compositions, respectively. In contrast, only 0.017 and $0.0035 \%$ of the initial conductivity was retained for $\mathrm{Cu}$ and $30 \mathrm{Zn}$, respectively. The XRD patterns of these samples after the corrosion test revealed the formation of $\mathrm{Cu}_{2} \mathrm{O}$ and $\mathrm{CuO}$ in all samples (Fig. 3C), suggesting that the resistivity increase is due to oxidation of $\mathrm{Cu}$. The XRD peak intensities of copper oxides of $\mathrm{Cu}$ and $30 \mathrm{Zn}$ were stronger than those of the other samples (Fig. 3C). This would explain that more oxides were formed in $\mathrm{Cu}$ and $30 \mathrm{Zn}$. In order to eliminate a possibility that a large amount of amorphous oxide was formed in each sample, the energy-dispersive X-ray spectroscopy (EDX) was performed. The results were consistent with the XRD data, i.e., less oxygen was detected by EDX for $1 \mathrm{Sn}, 5 \mathrm{Ag}, 5 \mathrm{Ni}$, and $30 \mathrm{Ni}$ compared to $\mathrm{Cu}$ and $30 \mathrm{Zn}$ (Table S1).

TEM images were obtained for $\mathrm{Cu}$ and $30 \mathrm{Ni}$ NPs before and after corrosion testing at $85^{\circ} \mathrm{C}, 85 \% \mathrm{RH}$ for $1 \mathrm{hr}$ and $50 \mathrm{hrs}$ (Figure S3). Spherical NPs were initially observed for each sample. After $1 \mathrm{hr}$, a thin oxide layer was formed on each sample. The $\mathrm{Cu}$ NPs were completely oxidized after $50 \mathrm{hrs}$. In contrast, the $30 \mathrm{Ni}$ NPs were protected by the passivating oxide on the surface of the NPs, and retained their spherical shape after $50 \mathrm{hrs}$. EDX measurements were further carried out to confirm the formation of passive oxide layer on the $30 \mathrm{Ni}$ NPs after corrosion testing for $50 \mathrm{hrs}$ (Fig. 5). The oxide layer was clearly observed on the surface of $30 \mathrm{Ni}$ NPs in the corresponding scanning-mode TEM (STEM) image (BF, bright field), and the oxide layer contained much larger amounts of $\mathrm{Ni}$ and $\mathrm{O}$ than the metal core that contains more $\mathrm{Cu}$ (see and compare the elemental mappings of $\mathrm{Cu}, \mathrm{Ni}$ and $\mathrm{O}$, and also the corresponding composed image (Compo)). Since an alloying of $\mathrm{Cu}$ with $\mathrm{Ni}$ or a coating of $\mathrm{Ni}$ on $\mathrm{Cu}$ has been employed to improve the oxidation resistance of $\mathrm{Cu}$ by forming $\mathrm{Ni}$-containing compact passive oxide layer ${ }^{43,44}$, the improved oxidation resistance of $30 \mathrm{Ni}$ NPs in this work would be reasonable. Moreover, although clear elemental EDX mappings from the other alloy NPs could not be taken because of the low content of the secondary metals, the similar phenomenon can be expected for the improved oxidation resistance in $1 \mathrm{Sn}, 5 \mathrm{Ag}$, and $5 \mathrm{Ni}$.

With further improvement of their electrical conductivity and corrosion resistance, $\mathrm{Cu}$ alloy NPs prepared by WE could be used for the production of affordable conductive inks for printed electronics ${ }^{45-51}$. The reproducibility of this method would become sufficient once the corrosion resistance of NPs was further improved. The ability of the conductive inks to be deposited by more advanced printing techniques such as inkjet and screen printings should be evaluated in the near future.

\section{Conclusion}

This article demonstrated that WE of metal wires in an aqueous ascorbic acid solution was a simple and environmentally friendly approach to the production of NPs consisting of $\mathrm{Cu}$ and $\mathrm{Cu}$ alloys for conductive inks. $\mathrm{Cu}$ and $\mathrm{Cu}$ alloy NPs produced by WE exhibited electrical resistivities as low as $5 \times 10^{-5} \Omega \mathrm{m}$ after drying in air at room temperature, and $1.6 \times 10^{-6} \Omega \mathrm{m}$ after sintering in $\mathrm{H}_{2}$. Cu NPs alloyed with $1 \% \mathrm{Sn}, 5 \% \mathrm{Ag}, 5 \% \mathrm{Ni}$ and $30 \% \mathrm{Ni}$ had electrical conductivities similar to $\mathrm{Cu}$, but remained conductive after $24 \mathrm{hrs}$ at $85^{\circ} \mathrm{C}$ and $85 \% \mathrm{RH}$. It is worth mentioning that the best resistivity achieved in this work was still 3000 time (after drying) and 100 times (after sintering) higher than bulk $\mathrm{Cu}$ value. Nevertheless, we hope this work motivates additional study of combining WE with chemical modification of the explosion medium to control the composition and surface chemistry of NPs produced by WE.

\section{Methods}

Source of Wires. Macroscopic wires of $\mathrm{Cu}(0.079$ or $0.4 \mathrm{mM}$ (diameter), Arcor electronics, USA), Ag (0.0254 mM, Superpure chemicals, USA), Ni ( $0.25 \mathrm{~mm}$, Sigma-Aldrich, USA), tinned Cu ( $99 \mathrm{Cu}-1 \mathrm{Sn}, 0.4 \mathrm{~mm}$, Arcor electronics, USA), and brass (70Cu-30Zn, $0.4 \mathrm{~mm}$, Malin, USA) were cut into $60 \mathrm{~mm}$ segments to match the distance between electrodes in a stainless-steel sample chamber (IMNano, Korea). The 1Sn and 30Zn NPs were prepared by exploding wires with compositions of $99 \mathrm{Cu}-1 \mathrm{Sn}$ and $70 \mathrm{Cu}-30 \mathrm{Zn}$. The $5 \mathrm{Ag}$, $5 \mathrm{Ni}$, and $30 \mathrm{Ni} \mathrm{NPs}$ 

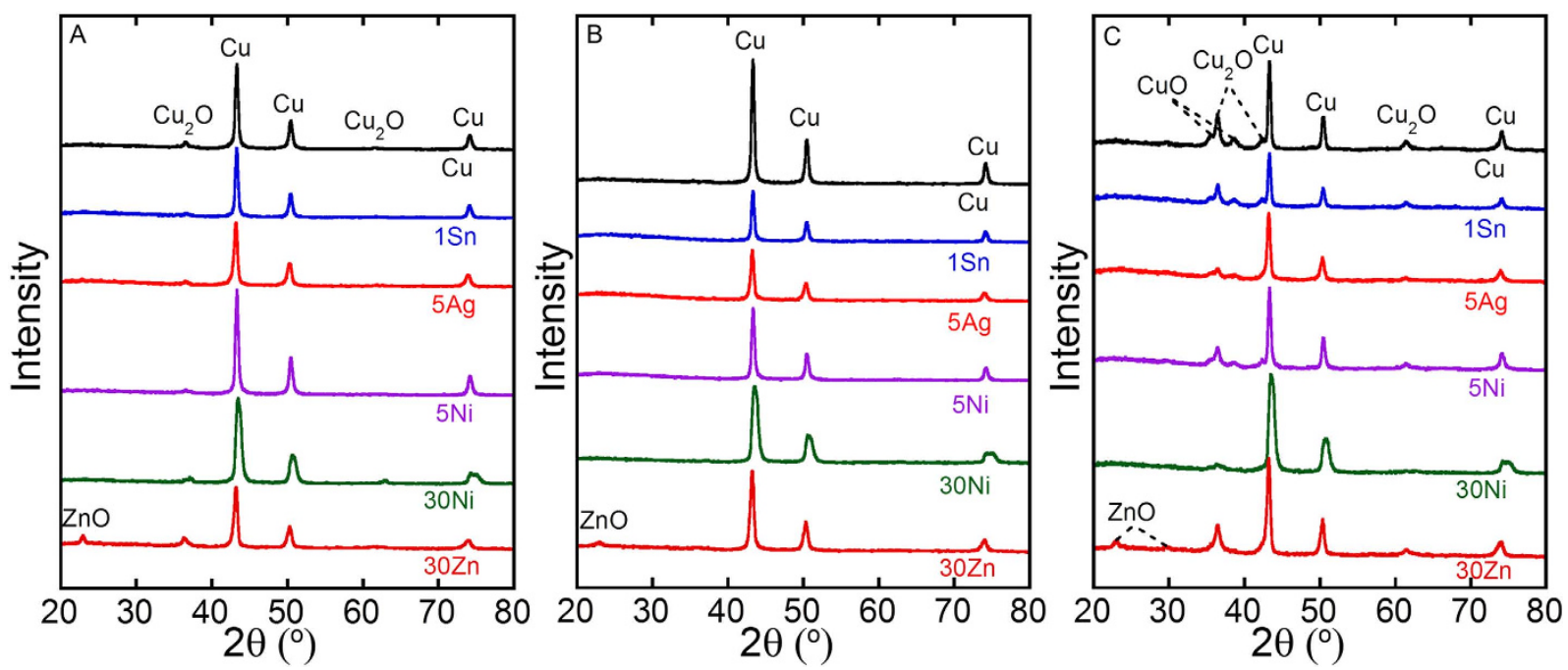

Figure 3. XRD patterns of samples prepared by WE in $200 \mathrm{mM}$ ascorbic acid aqueous solution: (A) asprepared, (B) sintered, (C) sintered followed by corrosion.

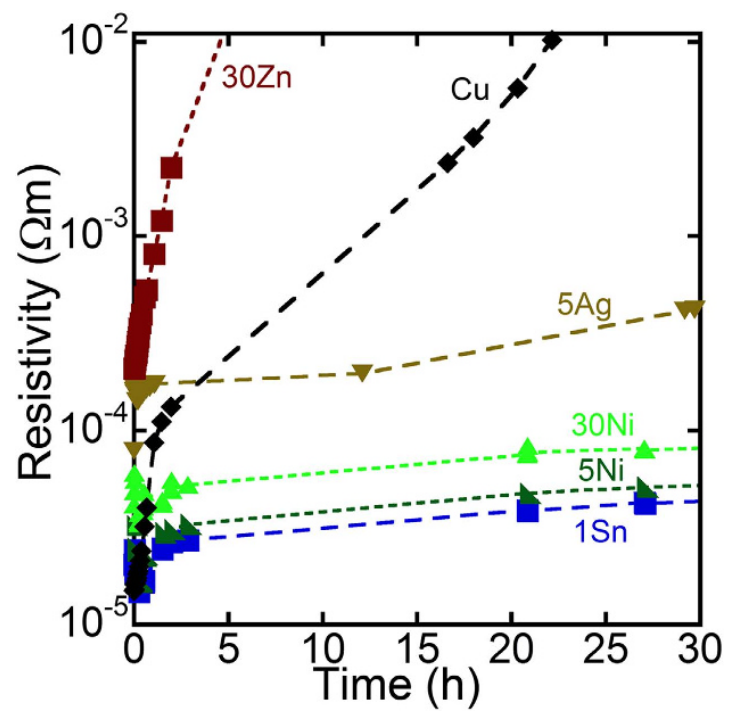

Figure 4. Time-dependent conductivity attenuation during exposure to $85^{\circ} \mathrm{C}$ and $85 \% \mathrm{RH}$.

were prepared by exploding two separate wires that were twisted together: $1 \mathrm{Cu}$ wire $(60 \times 0.4 \mathrm{~mm})$ and $13 \mathrm{Ag}$ wires $(60 \times 0.0254 \mathrm{~mm})$ for $5 \mathrm{Ag}$; $1 \mathrm{Cu}$ wire $(60 \times 0.4 \mathrm{~mm})$ and $1 \mathrm{Ni}$ wire $(8.4 \times 0.25 \mathrm{~mm})$ for $5 \mathrm{Ni}$; and $23 \mathrm{Cu}$ wires $(60 \times 0.079 \mathrm{~mm})$ and $1 \mathrm{Ni}$ wire $(60 \times 0.25 \mathrm{~mm})$ for $30 \mathrm{Ni}$

Preparing Metal NPs by WE. Figure 6A shows a scheme of the wire exploder for preparation of metal NPs. Two $20 \mu \mathrm{F}$ capacitors (NOC20M20CS, Condenser products, USA) connected in series were charged with a high-voltage direct current power supply (Series ER, Glassman high voltage, USA) with an appropriate voltage for each metal wire. The voltage was chosen to generate 5 times more energy than that required for vaporization of the wire $\left(E_{\text {wire }}\right)$, which is calculated as follows:

$$
E_{\text {wire }}=\left[1000\left(\Delta H_{f}+\Delta H_{v}\right)+\left(T_{b}-273\right) C_{p}\right] \div M \times W
$$

where $\Delta H_{f}$ and $\Delta H_{\nu}$ are heat of fusion and vaporization, $T_{b}$ is boiling temperature, $C_{p}$ is heat capacity, $M$ is the atomic weight of the metal, and $W$ is the mass of the wire.

The chamber was filled with $550 \mathrm{ml}$ of deionized water or an aqueous solution of ascorbic acid (>99\%, Alfa Aesar, USA) before placing the wire between the electrodes through the nozzle of the chamber (Fig. 6A). Current was passed from the capacitor through the wire by closing the spark gap switch, which was connected with coaxial cables to the positive and negative electrodes of the capacitors. The voltage and current profiles during WE were 

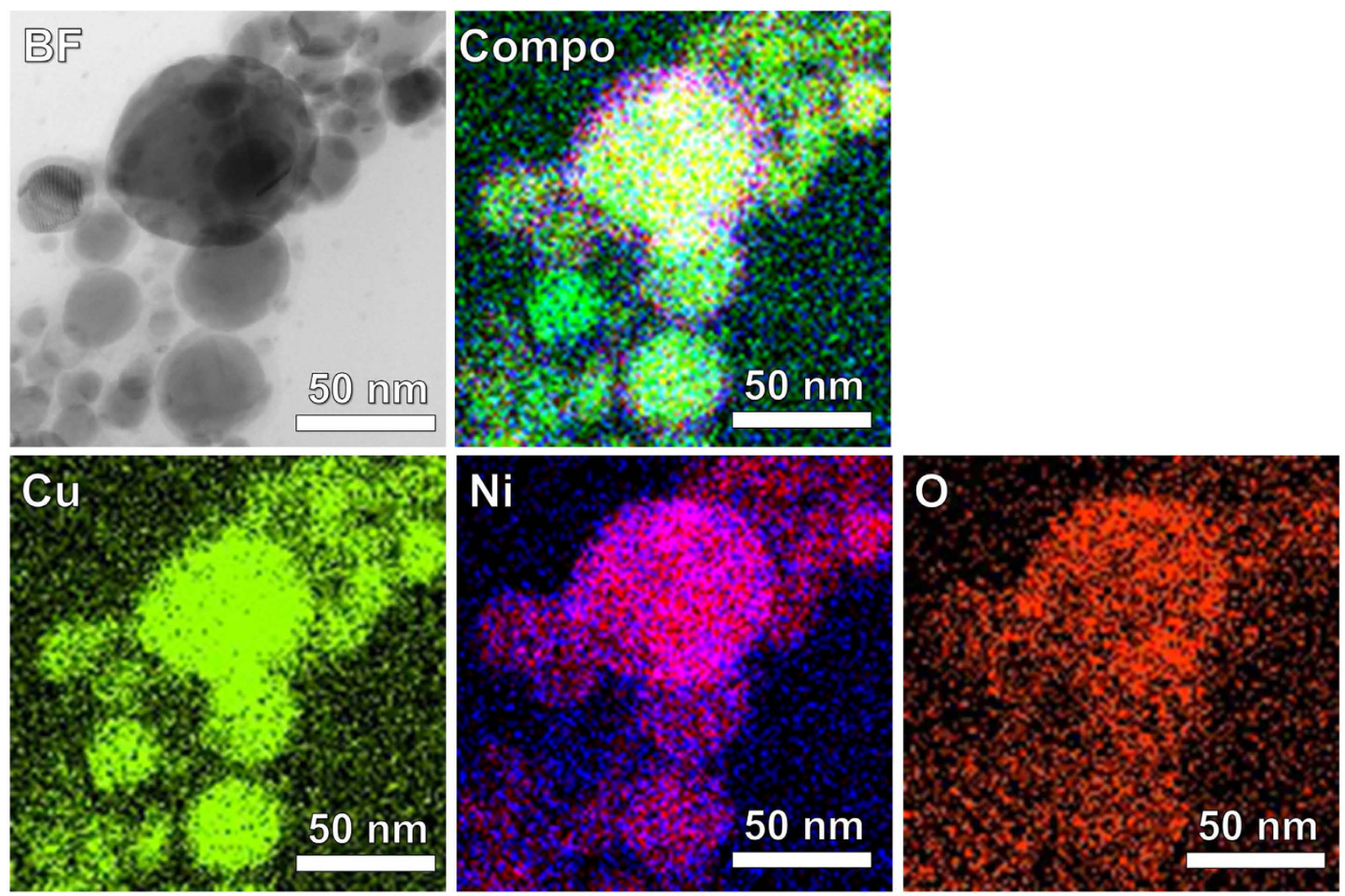

Figure 5. STEM image (BF, bright field) of $30 \mathrm{Ni}$ after corrosion testing for $\mathbf{5 0}$ hrs. The corresponding EDX mappings for $\mathrm{Cu}, \mathrm{Ni}$ and $\mathrm{O}$ are also shown. The Compo image is composed of overlapped $\mathrm{Cu}, \mathrm{Ni}$, and $\mathrm{O}$ mappings.

A Capacitor Switch

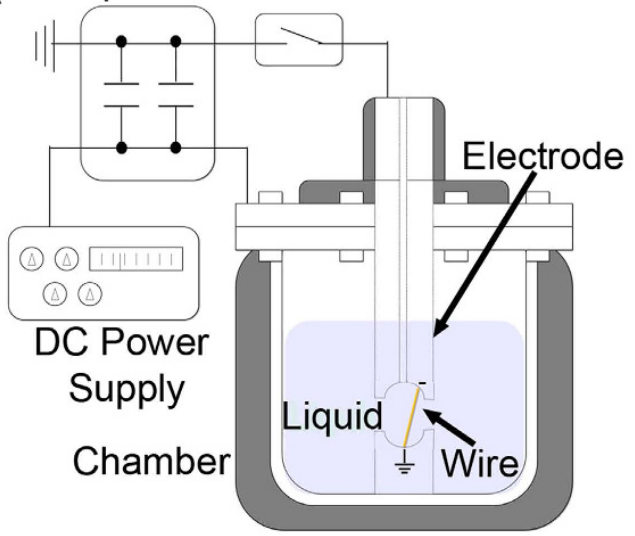

B

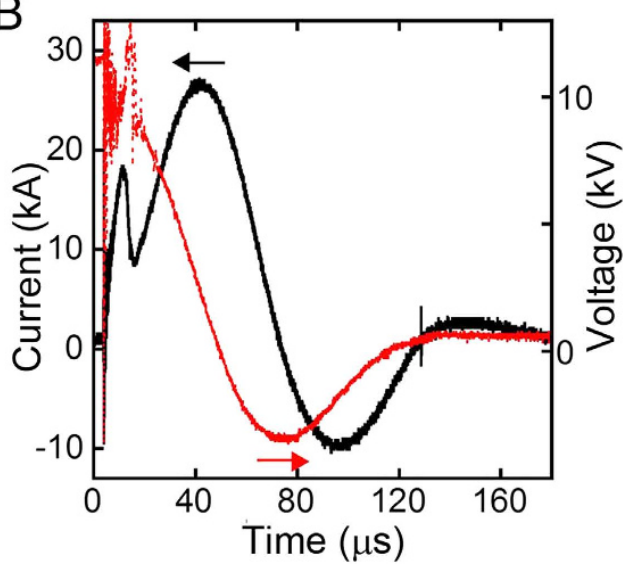

Figure 6. (A) Illustration of the wire exploder. (B) Dynamics of the voltage and current between the electrodes during $\mathrm{WE}$ of $\mathrm{Cu}$ in $200 \mathrm{mM}$ ascorbic acid aqueous solution.

measured using a digitized oscilloscope (DSO-5200A USB, Hantek, China) connected to a high-voltage probe (P6015A, Tektronix, USA) and a current transformer (Model 3-0.002, Stangenes Industries, USA). As shown in Fig. $6 \mathrm{~B}$, the voltage and current profile during $\mathrm{WE}$ of $\mathrm{Cu}$ features a sharp current rise and drop caused by Joule heating and subsequent explosion. A secondary current rise was caused by the inductive oscillation that results from plasma formation in the vaporized metal ${ }^{25,38}$.

After each explosion, a new wire was inserted through the chamber nozzle. This procedure was repeated 5-10 times in order to obtain a sufficient amount of NPs for conductivity tests. The obtained NPs were concentrated by centrifugation of the solution at $1500 \mathrm{rpm}$, followed by removal of the transparent supernatant, to obtain suspension with approximately $40 \%$ NPs by volume. Since the stability of the NP dispersion is relatively low, the centrifugation and replacement of the supernatant should be quickly carried out after the explosion of the wires. 
Characterization. Conductive lines were drawn by drop-casting of $15 \mu \mathrm{l}$ of solution containing $40 \mathrm{vol} \% \mathrm{NPs}$ in a Scotch tape template with a $2 \times 15 \mathrm{~mm}$ hole (see Figure S4). After the solvent was completely evaporated, some lines were sintered at $200^{\circ} \mathrm{C}$ in $\mathrm{H}_{2}$ for $30 \mathrm{~min}$. The thicknesses of the lines were measured using a profilometer (Dektak 150, Bruker, USA), and the resistivity was calculated from the thicknesses and resistances obtained with a four-point probe (SP4, Lucas signatone, USA). XRD measurements were performed with an X-ray diffractometer (X'pert pro MRD HR, Panalytical, UK). SEM and TEM observations were carried out using scanning (XL30, FEI, USA) and transmission (Tecnai G2 twin, FEI, USA, JEM-2100F, JEOL, Japan) electron microscopes, respectively. Since the sintered samples were baked together and difficult to scrape off, the as-prepared samples were first placed on TEM grids and then sintered. EDX analyses were done using an energy-dispersive X-ray spectroscope (2300T, JEOL, Japan) equipped with the JEM-2100F. The attenuation of the conductivity of the sintered lines under $85^{\circ} \mathrm{C}$ and $85 \%$ relative humidity $(\mathrm{RH})$ was recorded with a multimeter ( $87 \mathrm{~V}$ true RMS, Fluke, Canada), with the probes in the humidity controlled oven (TestEquity $200 \mathrm{H}$, USA) which contained the samples. Since the multimeter was attached to thin and long stainless steel wires in order to connect to the samples inside the oven, resistivities lower than $1.0 \times 10^{-5} \Omega$ m could not be measured.

\section{References}

1. Jeong, S. et al. Combined role of well-dispersed aqueous Ag ink and the molecular adhesive layer in inkjet printing the narrow and highly conductive Ag features on a glass substrate. J. Phys. Chem. C. 114, 22277-22283 (2010).

2. Kamyshny, A. \& Magdassi, S. Conductive nanomaterials for printed electronics. Small 10, 3515-3535 (2014).

3. Wu, H. et al. Electrospun metal nanofiber webs as high-performance transparent electrode. Nano Lett. 10, 4242-4248 (2010).

4. Park, S. et al. Preparation of conductive nanoink using pulsed-wire-evaporated copper nanoparticles for inkjet printing. Mater. Trans. 53, 1502-1506 (2012)

5. Teng, K. F. \& Vest, R. W. A microprocessor-controlled ink jet printing system for electronic circuits. IEEE Trans. Ind. Electron. 35, 407-412 (1988)

6. Cuk, T., Troian, S. M., Hong, C. M. \& Wagner, S. Using convective flow splitting for the direct printing of fine copper lines. Appl. Phys. Lett. 77, 2063-2065 (2000).

7. Magdassi, S., Kamyshny, A., Vinetsky, Y., Bassa, A. \& Abo, R. M. Ink-jet inks containing metal nanoparticles. Patent, PCT/ IL2002/000859 (2002).

8. Fuller, S. B., Wilhelm, E. J. \& Jacobson, J. M. Ink-Jet Printed Nanoparticle Microelectromechanical Systems. IEEE ASME J. Microelectromech, Syst. 11, 54-60 (2002).

9. Hu, L., Hecht, D. S. \& Gruner, G. Infrared transparent carbon nanotube thin films. Appl. Phys. Lett. 94, 081103 (3 pages) (2009).

10. Stejskal, J. Conducting polymer-silver composites. Chem. Paper. 67, 814-848 (2013).

11. Xia, X. P., Xie, C. S., Cai, S. Z., Yang, Z. H. \& Yang, X. L. Corrosion characteristics of copper microparticles and copper nanoparticles in distilled water. Corros. Sci. 48, 3924-3932 (2006).

12. Magdassi, S., Grouchko, M. \& Kamyshny, A. Copper nanoparticles for printed electronics: routes towards achieving oxidation stability. Materials 3, 4626-4638 (2010).

13. Luechinger, N. A., Athanassiou, E. K. \& Stark, W. J. Graphene-stabilized copper nanoparticles as an air-stable substitute for silver and gold in low-cost ink-jet printable electronics. Nanotechnology 19, 445201-445206 (2008).

14. Lee, Y., Choi, J. R., Lee, K. J., Stott, N. E. \& Kim, D. Large-scale synthesis of copper nanoparticles by chemically controlled reduction for applications of inkjet-printed electronics. Nanotechnology 19, 415604-415607 (2008).

15. Jeong, S. et al. Controlling the thickness of the surface oxide layer on $\mathrm{Cu}$ nanoparticles for the fabrication of conductive structures by ink-jet printing. Adv. Func. Mater. 18, 679-686 (2008).

16. Engels, V., Benaskar, F., Jefferson, D. A., Johnson, B. F. G. \& Wheatley, A. E. H. Nanoparticulate copper-routes towards oxidative stability. Dalton Trans. 39, 6496-6502 (2010).

17. Grouchko, M., Kamyshny, A. \& Magdassi, S. Formation of air-stable copper-silver core-shell nanoparticles for inkjet printing. J. Mater. Chem. 19, 3057-3062 (2009).

18. Hambrock, J., Schroter, M. K., Birkner, A., Woll, C. \& Fischer, R. A. Nano-brass: Bimetallic copper/zinc colloids by a nonaqueous organometallic route using $\left[\mathrm{Cu}\left(\mathrm{OCH}(\mathrm{Me}) \mathrm{CH}_{2} \mathrm{NMe}_{2}\right)_{2}\right]$ and $\mathrm{Et}_{2} \mathrm{Zn}$ as precursors. Chem. Mater. 15, 4217-4222 (2003).

19. Cable, R. E. \& Schaak, R. E. Solution synthesis of nanocrystalline $\mathrm{M}-\mathrm{Zu}(\mathrm{M}=\mathrm{Pd}, \mathrm{Au}, \mathrm{Cu})$ intermetallic compounds via chemical conversion of metal nanoparticle precursors. Chem. Mater. 19, 4098-4104 (2007).

20. Tan, K. S. \& Cheong, K. Y. Advances of Ag, Cu, and Ag-Cu alloy nanoparticles synthesized via chemical reduction route. J. Nanopart. Res. 15, 1537 (29 pages) (2013).

21. Andolina, C. M. et al. Photoluminescent Gold-Copper nanoparticle alloys with composition-tunable near-infrared emission. J. Am. Chem. Soc. 135, 5266-5269 (2013).

22. Sugano, Y. et al. Supported Au-Cu bimetallic alloy nanoparticles: An aerobic oxidation catalyst with regenerable activity by visiblelight irradiation. Angew. Chem. Int. Ed. 52, 5295-5299 (2013).

23. Ferk, G. et al. The synthesis and characterization of nickel-copper alloy nanoparticles with a narrow size distribution using sol-gel synthesis. Mater. Lett. 124, 39-42 (2014).

24. McGrath, J. R. Exploding wire research 1774-1963. NRL memorandum report 1698, 1 (17 pages) (1966).

25. Bora, B. et al. Understanding the mechanism of nanoparticle formation in wire explosion process. J. Quant. Spectrosc. Rafiat. Transfer 117, 1-6 (2013).

26. Karioris, F. G. \& Fish, B. R. An exploding wire aerosol generator. J. Colloid. Sci. 17, 155-161 (1962).

27. Kotov, Y. A. Electric explosion of wires as a method for preparation of nanopowders. J. Nanopart. Res. 5, 539-550 (2003).

28. Azarkevich, E. I., Ilyin, A. P., Tikhonov, D. V. \& Yablunovski, G. V. Electric explosion sintering ultrafine powders of alloys and intermetallides. Zh. Russ. Fiz. Chem. Mater. Treatment 4, 85-88 (1997).

29. Wang, Q., Yang, H. B., Shi, J. L. \& Zou, G. T. Preparation and characterization of nanocrystalline powders of Cu-Zn alloy by wire electrical explosion method. Mater. Sci. Eng. A 307, 190-194 (2001).

30. Fu, Y. \& Shearwood, C. Characterization of nanocrystalline TiNi powder. Scripta Mater. 50, 319-323 (2004).

31. Kim, W. et al. A new method for the production of alloy nanoparticles by electrical wire explosion. Mater. Trans. 48, 1973-1974 (2007).

32. Suwa, K. et al. Synthesis of Ni-Cu nanoparticles by pulsed wire discharge and their compositional distribution. Jpn. J. Appl. Phys. 47, 775-779 (2008)

33. Yun, J. Y. et al. Characteristics of Fe-Cr-Al Alloy Nanopowders Prepared by Electrical Wire Explosion Process under Liquid Media. Mater. Trans. 52, 250-253 (2011).

34. Tokoi, Y. et al. Phase control of Ti-Fe nanoparticles prepared by pulsed wire discharge. Jpn. J. Appl. Phys. 50, 01BJ06-1 (6 pages) (2011).

35. Bac, L. H., Ryu, H. J., Kim, B. K., Kim, J. S. \& Kim, J. C. Production and determination of the magnetic properties of the Fe-36Ni nanopowder via electrical explosion of wire in water and compacted alloy. J. Nanosci. Nanotechnol. 11, 6433-6436 (2011). 
36. Ishihara, S. et al. Synthesis of intermetallic NiAl compound nanoparticles by pulsed wire discharge of twisted $\mathrm{Ni}$ and $\mathrm{Al}$ wires. Intermetallics 23, 134-142 (2012).

37. Yun, J. Y. et al. Large-scale synthesis and $\mathrm{CO}$ oxidation study of $\mathrm{FeCr}$ alloy supported $\mathrm{Pt}$ nanocatalyst by electrical wire explosion process. Catal. Lett. 142, 326-331 (2012).

38. Cho, C., Choi, Y. W. Kang, C. \& Lee, G. W. Effects of the medium on synthesis of nanopowders by wire explosion process. Appl. Phys. Lett. 91, 141501 (3 pages) (2007).

39. Wu, C., Mosher, B. P. \& Zeng, T. One-step green route to narrowly dispersed copper nanocrystals. J. Nanopart. Res. 8, 965-969 (2006).

40. Xiong, J., Wang, Y., Xue, Q. \& Wu, X. Synthesis of highly stable dispersions of nanosized copper particles using L-ascorbic acid. Green Chem. 13, 900-904 (2011).

41. Shankar, S., Teng, X. \& Rhim, J.-W. Properties and characterization of agar/CuNP bionanocomposite films prepared with different copper salts and reducing agents. Carbohydrate Polymers 114, 484-492 (2014).

42. Feng, J., Ju, Y., Liu, J., Zhang, H. \& Chen, X. Polyethyleneimine-templated copper nanoclusters via ascorbic acid reduction approach as ferric ion sensor. Anal. Chim. Acta 854, 153-160 (2015).

43. Zhang, Q., Park, K. \& Cao, G. Synthesis of ZnO aggregates and their application in dye-sensitized solar cells. Mater. Matters 5.2, 32 (13 pages) (2010).

44. Rathmell, A. R., Nguyen, M., Chi, M. \& Wiley, B. J. Synthesis of oxidation-resistant cupronickel nanowires for transparent conducting nanowire networks. Nano Lett. 12,3193-3199 (2012).

45. Stewart, I. E. et al. Solution-processed copper-nickel nanowire anodes for organic solar cells. Nanoscale 6, 5980-5988 (2014).

46. Russo, A. et al. Pen-on-paper flexible electronics. Adv. Mater. 23, 3426-3430 (2011).

47. Magdassi, S., Bassa, A., Vinetsky, Y. \& Kamyshny, A. Silver nanoparticles as pigments for water-based ink-jet inks. Chem. Mater. 15, 2208-2217 (2003).

48. Bieri, N. R., Chung, J., Haferl, S. E., Poulikakos, D. \& Grigoropoulos, C. P. Microstructuring by printing and laser curing of nanoparticle solutions. Appl. Phys. Lett., 82, 3529-3531 (2003).

49. Perelaer, J., Gans, B.-J. \& Schubert, U. S. Ink-jet printing and microwave sintering of conductive silver tracks. Adv. Mater. 18, 2101-2104 (2006).

50. Wakuda, D., Kim, K.-S. \& Suganuma, K. Room-temperature sintering process of Ag nanoparticle paste. IEEE Trans. Compon. Packag. Tech. 32, 627-632 (2009).

51. Magdassi, S., Grouchko, M., Berezin, O. \& Kamyshny, A. Triggering the Sintering of Silver Nanoparticles at Room Temperature. ACS Nano 4, 1943-1948 (2010).

\section{Acknowledgements}

This work was partially supported by the collaborative research grant from Korea Electrotechnology Research Institute (No. 13-02-N0104-01). Z.-F.C. also thanks the National Natural Science Foundation of China (21405114, 21573160) for financial support.

\section{Author Contributions}

G.K. and Y.-C.H. conceived and designed the experiments. G.K., S.A. and I.E.S. conducted the experiments. M.C. and Z.C. provided suggestions throughout the project. All authors discussed the results and reviewed the manuscript.

\section{Additional Information}

Supplementary information accompanies this paper at http://www.nature.com/srep

Competing financial interests: The authors declare no competing financial interests.

How to cite this article: Kawamura, G. et al. Production of Oxidation-Resistant Cu-Based Nanoparticles by Wire Explosion. Sci. Rep. 5, 18333; doi: 10.1038/srep18333 (2015).

(c) (1) This work is licensed under a Creative Commons Attribution 4.0 International License. The images or other third party material in this article are included in the article's Creative Commons license, unless indicated otherwise in the credit line; if the material is not included under the Creative Commons license, users will need to obtain permission from the license holder to reproduce the material. To view a copy of this license, visit http://creativecommons.org/licenses/by/4.0/ 